\title{
Commentary: Finally, data to support dogma
}

\author{
Scott I. Reznik, MD
}

\footnotetext{
From the Division of General Thoracic Surgery, Department of Cardiovascular and Thoracic Surgery, University of Texas Southwestern Medical Center, Dallas, Tex.

Disclosures: Author has nothing to disclose with regard to commercial support.

Received for publication Feb 8, 2019; accepted for publication Feb 9, 2019; available ahead of print April 17, 2019.

Address for reprints: Scott I. Reznik, MD, 5323 Harry Hines Blvd, MC 8879, Dallas TX 75390-8879 (E-mail: sireznik@yahoo.com).

J Thorac Cardiovasc Surg 2019;158:568-9

$0022-5223 / \$ 36.00$

Copyright (c) 2019 by The American Association for Thoracic Surgery

https://doi.org/10.1016/j.jtcvs.2019.02.042
}

In this issue of the Journal, McCall and colleagues ${ }^{1}$ present $^{-}$ a study of right ventricular (RV) function and pulmonary artery elasticity after major lung resection. It is intuitive and dogmatic that RV afterload rises after lung resection as a result of the loss of volume of the pulmonary vascular bed; however, this has not been reliably demonstrated with invasive measures such as pulmonary artery catheters. ${ }^{2}$ Many investigators have tried to correlate transthoracic echography findings, but without success. ${ }^{3}$ Several groups, including that of McCall and colleagues ${ }^{4}$ have used speckle-tracking echocardiography to evaluate RV strain, which is a promising technique. ${ }^{5,6}$ Cardiovascular magnetic resonance imaging (CMR) has become the criterion standard to evaluate RV function. In addition, this technique allows measurement of static and pulsatile components of RV afterload and of the hemodynamics of the main and branch pulmonary arteries.

Not surprisingly, this study of McCall and colleagues ${ }^{1}$ confirms what most would postulate, that the RV may exhibit dysfunction after lung resection and that changes in pulmonary artery distensibility are from the operative side. The changes in the cardiopulmonary unit persist at 2 months, which may explain the prolonged or limited recovery that plagues some patients.

How do we incorporate these findings into clinical practice? Patients who have a poor functional result after lung resection out proportion to the loss of pulmonary parechyma may have limited RV performance. As McCall and colleagues ${ }^{1}$ state, this is a proof of concept study, and they did not specifically correlate CMR findings and clinical outcomes. McCall and colleagues ${ }^{1}$ do, however, provide a teaser. Lower transfer factor for carbon monoxide is associated with a larger decrement in $\mathrm{RV}$ ejection fraction on postoperative day 2, and lower postoperative day $2 \mathrm{RV}$ ejection fraction was associated with a longer intensive care stay (Figures E5 and E6 in the article of McCall and colleagues ${ }^{1}$ ). Increased understanding of the effect of lung resection on the cardiopulmonary unit would improve risk stratification, predict

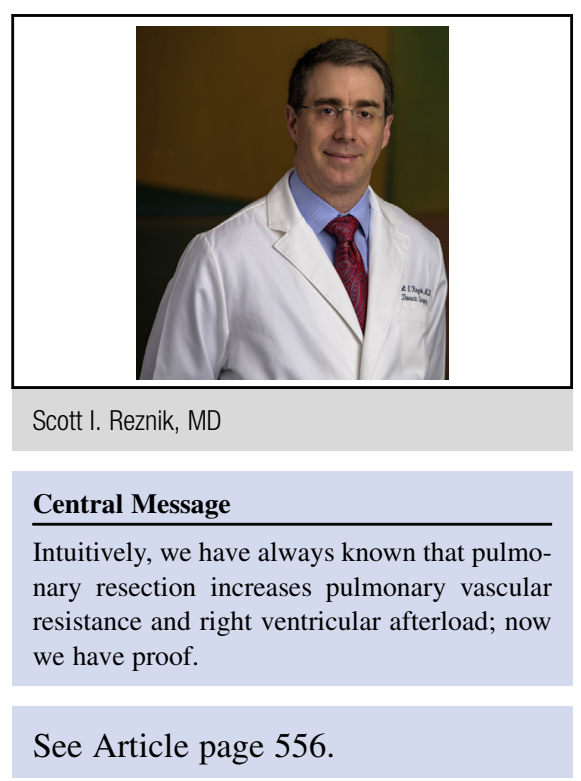

functional result, affect preoperative decision making, and perhaps guide perioperative care.

CMR may not be available for routine use; however, it may be considered for marginal patients. Furthermore, CMR may be used to validate less invasive methods, such as speckle-tracking echocardiography, transfer factor for carbon monoxide, and serum biomarkers. We should remain circumspect in ordering CMR, because this is a small study from a single center. All patients underwent resection via thoracotomy, which is associated with increased cytokine release and proinflammatory markers that may have an effect on cardiopulmonary performance. Depressed respiratory mechanics may result in hypoventilation and increased pulmonary vascular resistance and RV dysfunction. Most of the changes detected on postoperative 2 persist at 2 months, however, perhaps confirming the role of the lung resection. It would be interesting to see whether lesser effects on RV function are present after less invasive resections. Two months may not be long enough to allow full recovery and adaptation of the cardiopulmonary unit. It will be necessary to replicate the findings in a larger patient population and to correlate the findings with clinical outcomes.

Regardless of these limitations, we now have proof of something we always assumed. Now we need to use this study as a springboard to better evaluation, counseling, and treatment of our patients. 


\section{References}

1. McCall PJ, Arthur A, Glass A, Corcoran DS, Kirk A, Macfie A, et al. The right ventricular response to lung resection. J Thorac Cardiovasc Surg. 2019;158: 556-65.e5.

2. Reed CE, Spinale FG, Crawford FA Jr. Effect of pulmonary resection on right ventricular function. Ann Thorac Surg. 1992;53:578-82.

3. Amar D, Burt ME, Roistacher N, Reinsel RA, Ginsberg RJ, Wilson RS. Value of perioperative Doppler echocardiography in patients undergoing major lung resection. Ann Thorac Surg. 1996;61:516-20.
4. McCall P, Soosay A, Kinsella J, Sonecki P, Shelley B. The utility of transthoracic echocardiographic measures of right ventricular systolic function in a lung resection cohort. Echo Res Pract. 2019;6:7-15.

5. Smolarek D, Gruchala M, Sobiczewski W. Echocardiographic evaluation of right ventricular systolic function: the traditional and innovative approach. Cardiol $\mathrm{J}$. 2017;24:563-72.

6. Wang Z, Yuan J, Chu W, Kou Y, Zhang X. Evaluation of left and right ventricular myocardial function after lung resection using speckle tracking echocardiography. Medicine (Baltimore). 2016;95:e4290. 